\title{
THE PRO-CIRCULAR CHANGE MODEL (P-CCM)- PROPOSING A FRAMEWORK FACILITATING BEHAVIOURAL CHANGE TOWARDS A CIRCULAR ECONOMY
}

Zaneta Muranko ${ }^{1}$, Deborah Andrews ${ }^{1}$, Elizabeth J Newton ${ }^{1}$, Issa Chaer ${ }^{1}$, Philip Proudman ${ }^{2}$

${ }^{1}$ London South Bank University

2 The Bond Group, UK

Corresponding Author:

Zaneta Muranko, PhD Researcher

London South Bank University

School of Engineering

103 Borough Road

London SE1 OAA

murankoz@Isbu.ac.uk

Dr Deborah Andrews, Associate Professor

London South Bank University

School of Engineering

Dr Issa Chaer, Reader

London South Bank University

School of the Built Environment and Architecture

Dr Elizabeth J Newton, Senior Lecturer

London South Bank University

School of Applied Sciences

Philip Proudman, Sales and Marketing Director

The Bond Group

New Road

Sheerness

Kent ME12 1BB

Abstract

A Circular Economy is an economic and industrial system where resources are kept in use for as long as possible. This system is an alternative to the "take-make-use-dispose" path which is followed in many industries. Businesses can adopt a circular approach to production by implementing a range of alternative business models. These models require consumer acceptance, however there is currently a lack of knowledge and familiarity and with these models, which is preventing the development and adoption of a Circular Economy. There is little research on behaviour change with specific regard to the Circular Economy. This is due to the concepts' multidisciplinary scope which makes data collection methods expansive and challenging.

7) The Pro-Circular Change Model (P-CCM) is a novel theoretical framework, which uses a Theory of Planned Behaviour (TPB), Pro-Circular Values (P-CV) and Persuasive Communication (PC) to identify and influence behaviours that can support the development of a Circular Economy. For the purpose of the model, behaviours that are brought about due to the prioritising of resource-efficiency were defined as Pro-Circular.

\section{Keywords}

Circular Economy, Behaviour Change, Theory of Planned Behaviour, Persuasive Communication, Pro-Circular Behaviour 


\subsection{Introduction.}

The linear economy was established in the early days of the industrial revolution and is still prevalent in a significant majority of industries to date. It is based on the "take-make-use-dispose" system, where products are made, used and disposed of at the end of their life. This system can lead to resource overuse, waste and is founded on the naive assumption of an infinite material supply. While its practice is common, governments (European Commission, 2015a; DEFRA, 2015) and businesses are beginning to realise the potential and "importance of moving to a more sustainable economy" (DEFRA, 2015).

An alternative to the linear model is a Circular Economy. A circular economy is an economic and industrial system where resources are kept in use for as long as possible. In contrast to the linear economy it can eliminate waste, reduce environmental impacts of production and consumption, and provide resource security. It also has the potential to generate more jobs and sustain a competitive and growing economy (European Commission, 2015a).

A) The concept of a Circular Economy was first initiated by Walter Stahel in the 1970's. Stahel emphasised the importance of extending the lifecycle of products, as a way to achieve a more sustainable economy. As shown in his closed-loop framework, this is a result of consistently reusing, repairing, reconditioning and recycling products and components (Stahel, 1976chek; Stahel, 1982). In the 1990's, the Circular Economy was again advocated by Braungart and McDonough, who were proponents of the Cradle to Cradle approach. This approach focuses on closed-loop design and manufacture, however extends Stahel's concept of the Circular Economy to consider biological products. Braungart and McDonough, divided the Circular Economy into two distinct cycles - for biotic and abiotic products. (Broungart and McDonough, 2002).

Businesses in the abiotic sector can adopt a circular approach to production by implementing a range of alternative business models, such as: product-service systems (PSS), sharing platforms, maintenance and refurbishment or remanufacture (APPSRG and APPMG, 2014). However many businesses do not have sufficient knowledge of the above models to confidently divert away from the current linear-based norm (European Commission, 2014; Rizos et al., 2015). This knowledge gap results in many businesses overlooking the financial benefits and competitive advantages that a circular economy can bring (Ellen MacArthur Foundation, 2012). Some businesses may be cautious about how their end-user will respond to changes in their business models, which is also due to a lack of knowledge and familiarity with Circular Economy. For example products that are remanufactured or refurbished, are often wrongly perceived by the consumer to be of lower quality (APPSRG and APPMG, 2014), when this is not the case. Furthermore implementation of ProCircular Behaviour (P-CB) is often disregarded due the benefits (e.g. resource security, waste reduction) not being immediately apparent (Atherton, 2015).

There is currently a lack of research on consumer behaviour in regards to the Circular Economy (Ellen MacArthur Foundation, 2013). Data collection on this is still in its infancy due to its challenging (Atherton, 2015) and multi-disciplinary scope. Consequently, organisations such as the World Bank (2014) has called for further research into the influencers of psychological change in resource consumption.

This paper encourages further research into behaviour change by proposing a novel behavioural change model - The Pro-Circular Change Model ( $\mathrm{P}$ CCM). This theoretical model identifies a core set of behaviours and values that can identify an individual as being Pro-Circular. The model also shows how to design more effective interventions to encourage and promote Pro-Circular values and behaviours in target groups.

\subsection{Pro-Circular Behaviour (P-CB).}

\begin{tabular}{|l|l|l|}
\hline $\begin{array}{l}\text { Producer T) } \\
\text { offerings }\end{array}$ & $\begin{array}{l}\text { Consumer } \\
\text { behaviour }\end{array}$ & Outcomes \\
\hline $\begin{array}{l}\text { Selling } \\
\text { remanufacturig } \\
\text { products }\end{array}$ & $\begin{array}{l}\text { Buying } \\
\text { remanufactured } \\
\text { products }\end{array}$ & $\begin{array}{l}\text { Reduction of } \\
\text { waste, \& air, } \\
\text { water and soil } \\
\text { pollution }\end{array}$ \\
\hline $\begin{array}{l}\text { Providing } \\
\text { repairing } \\
\text { service }\end{array}$ & $\begin{array}{l}\text { Extending life } \\
\text { of owned } \\
\text { products }\end{array}$ & $\begin{array}{l}\text { More } \\
\text { education \& } \\
\text { training } \\
\text { and job } \\
\text { opportunities }\end{array}$ \\
\cline { 1 - 2 } $\begin{array}{l}\text { Product- } \\
\text { service } \\
\text { platforms }\end{array}$ & $\begin{array}{l}\text { Sharing } \\
\text { products }\end{array}$ & $\begin{array}{l}\text { growth of } \\
\text { local } \\
\text { businesses }\end{array}$ \\
\hline
\end{tabular}

Table 1. Pro-Circular Behaviours - parallel examples and shared social, environmental and economic impacts.

Many experts agree (e.g. European Commission, 2014b; DEFRA, 2015; Atherton, 2015; Ellen MacArthur Foundation, 2013), that moving to a 


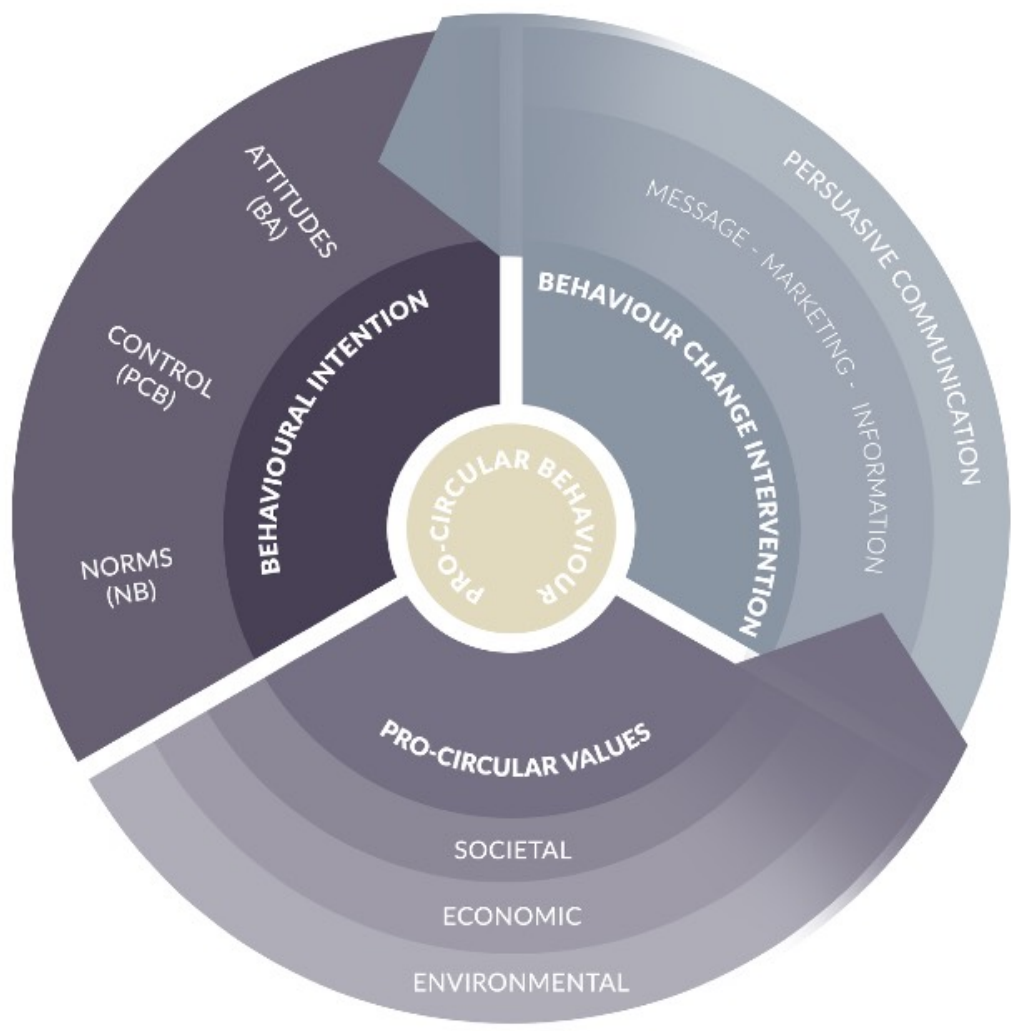

Figure 1. The Pro-Circular Change Model (P-CCM).

Circular Economy requires change to how people produce and consume products. Adoption of circular business models (e.g., remanufacture, maintenance service, product-service-systems) by both producers and consumers, can lead to favourable behaviours and advantageous outcomes (APPSRG, 2014; Zero Waste Scotland, 2016; Ellen MacArthur Foundation 2013). Examples of such corresponding behaviours and outcomes are shown in Table 1.

Literature on the Circular Economy frequently discusses behaviour change (e.g., The CIWM, 2014; The Scottish Government, 2016). However to date, behaviour has not been identified and defined in the Circular Economy domain. To distinguish specific behaviours that support the development of a Circular Economy, authors of this paper propose to define ProCircular Behaviour (P-CB) as "an action which is brought about due to prioritising resource-efficiency. This behaviour benefits or at least reduces damage to the environment, economy and society." (Muranko et al, 2017) K) In the abiotic Circular Economy system, these behaviours can be reusing, repairing, refurbishing, remanufacturing, recycling and borrowing or leasing products.

The Pro-Circular Behaviour (P-CB) shares some of its characteristics with an existing Pro-
Environmental Behaviour (PEB). As per definition, the $P E B$ is a kind of behaviour which "consciously seeks to minimise the negative impact of one's actions on the natural and built world" (Kollmuss and Agyeman 2002). Nonetheless, the PEB concentrates purely on the environmental impacts of one's action, omitting the economic and social factors. P-CB seeks to adopt these omissions and to include the economic and environmental factors.

$\mathrm{P}-\mathrm{CB}$ is the kind of behaviour the Pro-Circular Change Model aims to engender.

\subsection{The Pro-Circular Change Model (P-CCM).}

The Pro-Circular Change Model (P-CCM; Figure 1.) is a conceptual framework that aims to encourage the adoption of Pro-Circular Behaviours (P-CB). The framework could help to change consumer and organisational behaviours that are not considered beneficial to the development of a Circular Economy.

E) The framework can be used to campaign for behaviour change within targeted consumer groups that share similar characteristics, values and attitudes. The desired result being a change in the targets unfavourable behaviour towards the purchase, use or even disposal of a product. An unfavourable behaviour is a kind of action that shortens the lifecycle of a functional product or a component. For example, the 
demand for new products shortens the lifecycle of potentially repairable or remanufacturable products .

E2) The framework could be used to encourage behaviour in a given industry. For example, in the retail refrigeration industry, manufacturers could use the PCCM to encourage supermarkets to purchase remanufactured equipment. Similarly in the computing industry, manufactures could use PCCM to encourage individual consumers to purchase refurbished equipment. In practice, the PCMM would be embedded in marketing materials, such as adverts, emails or presentations. J) It is important, that the marketing interventions are strategically developed and delivered to target a specific segment of population in order to engage in a behaviour change more effectively (McKenzie-Mohr, 2000).

A shift in consumer behaviour can be a catalyst for producers and distributors to change their offerings and business models. The framework focuses on how the PPCM could support the closed-loop production of technical goods, rather than biological goods in the Circular Economy. The PCCM applicability to the biotic loop requires further investigation.

\subsubsection{How the P-CCM works.}

The suggested model functions on the basis that an intention to perform a Pro-Circular Behaviour ( $P$ $\mathrm{CB}$ ) is first identified by those wishing to encourage it and then favourably stimulated to instigate the behaviour change. It contains three key elements (Figure 1.): Behavioural Intention (BI), Pro-Circular Value (P-CV) and Behaviour Change Intervention $(\mathrm{BCl})$.

The first construct of the model, the Behavioural Intention (BI), uses the Theory of Planned Behaviour (TPB; Ajzen 1991) to measure a probability of performing a Pro-Circular Behaviour (P-CB) by an individual or a group. The second part of the model, which is the Pro-Circular Value (P-CV) stage, identifies social, economic and environmental values held by a subject. The last stage of the P-CCM aims to initiate Pro-Circular Behaviours (P-CB) by utilising the identified intentions $(\mathrm{BI})$ and values $(\mathrm{P}-\mathrm{CV})$ in the Behaviour Change Interventions (BCl).

The constructs of the P-CCM are explained in sections 3.1, 3.2 and 3.3.

\subsubsection{Why the P-CCM could be successful in supporting Pro-Circular behaviours.}

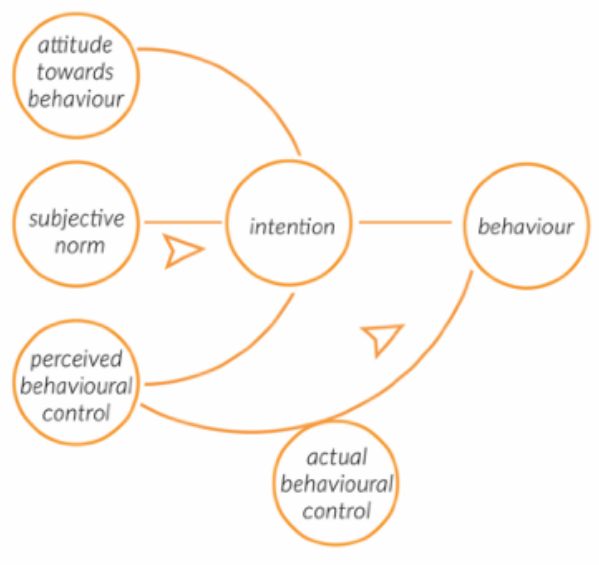

The P-CCM adopts the rules of the wellgrounded Theory of Planned Behaviour (TPB). Though proven to be a reliable predictor of behaviours when examined across a number of areas, such as: health, purchasing, consumption or sustainability, the theory (TPB) has never been utilised in the context of Circular Economy specifically. However, because some ProCircular Behaviours can relate to health, purchasing, consumption or sustainability, the assumptions are that the theory (TPB) could also be used to predict similar kind of behaviours akin to Circular Economy.

B) The theory (TPB) was previously applied to assess intentions to perform pro-environmental behaviours, such as saving energy (Greaves, Zibarras \& Stride, 2013), buying sustainable products (ref2b), recycling waste (ref3b) and using public transport (ref4b).

\section{C) There are a number of behaviour change} theories that are currently referenced in the proenvironmental domain such as Value-Belief-Norm or Theory of Reasoned Action. However neither of these theories specifically address Pro-Circular behaviours.

The Theory of Planned Behaviour has a wider range of variances than the Value-Belief-Norm theory (which focuses on the impact of moral components on a behaviour), has shown to be considerably more reliable when assessing recycling (ref) and conservation behaviours (ref.).

The inclusion of the perceptions of the behavioural control $(\mathrm{PCB})$ and consideration of the actual behavioural control $(A B C)$ in the Theory of Planned Behaviour makes the method a stronger predictor of behaviours than the Theory of Reasoned Action, which does not consider these variables (Madden et al, 1992). Specifically in context of the 


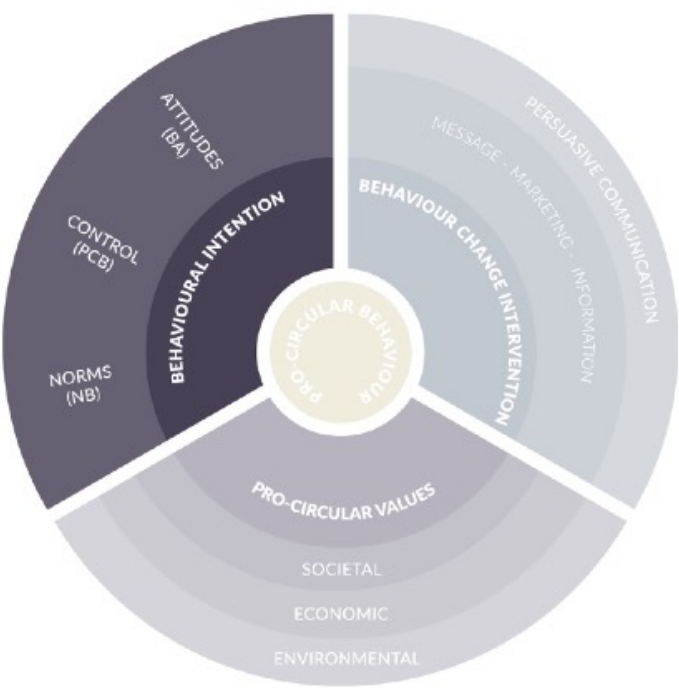

Figure 2. The P-CCM: Behavioural Intention (BI) Stage.

behavioural intention (BI) to reuse, repair, refurbish, remanufacture, recycle and borrow or lease products, a perception of behavioural control (PCB) and the ability to perform an action ( $A B C$ ) can have a significant impact on the conduct of such Pro-Circular behaviours.

Moreover, research shows that the appropriate interventions can change the variables of TPB and ultimately generate a positive shift in intentions and behaviour (Fife-Schaw, Sheeran, and Norman, 2007).

D)

This model supports the design of more

effective interventions, by using persuasive communication to target specific groups of consumers or business to business customers who share similar attitudes and Pro-Circular values towards certain ProCircular behaviours. Persuasive communication can be embedded in both verbal and written communications. This type of intervention is commonly used alongside with Theory of Planned Behaviour. Persuasive attitudinal, normative and control messages can influence a behavioural intention (BI) of an individual or a group and ultimately impact their behaviour (Ajzen, 1996).

Theorists argue that values are considered to have a significant impact on attitudes (Stern, 1999) and can explain certain behaviours (Ajzen, 2012). For example, in the existing model of Environmental Concern (Stern, 1995) values are defined as one of the key influencers of pro-environmental behaviours. The environmental, as well as social and economic concerns are the three key Pro-Circular Values (P-CV) which the P-CCM aims to identify and utilise in behavioural interventions $\mathrm{Db}$ ) to increase the effectiveness of persuasion. It is possible that this form of intervention could also enhance Pro-Circular Values held by an individual or a group.

\subsection{Behavioural Intention (BI) to perform a Pro-Circular Behaviour (P-CB)}

According to the Theory of Planned Behaviour (TPB; Figure 3.; Ajzen, 1991), human behaviour is first initiated by and relies on the strength of a behavioural intention (BI). The intention to perform a behaviour (BI) is a result of beliefs about the outcomes of a behaviour (Attitudes towards Behaviour; $A B$ ), beliefs about the expectations of others (Subjective Norms; $\mathrm{SN}$ ) and beliefs about the presence of factors that enable a behaviour (Perceived Behavioural Control; $P C B)$. The more favourable attitude (AB), subjective norm (SC) and perceived behavioural control (PCB) are, the stronger one's behavioural intention (BI; Figure 2.) is. (Ajzen, 1991)

Figure 3. The Theory of Planned Behaviour (Ajzen, 1991)

\subsubsection{Behavioural Attitude (BA)}

Attitude is generally defined as "a psychological tendency that is expressed by evaluating a particular entity with some degree of favour or disfavour" (Eagly and Chaiken, 1993). Attitudes are considered to have an influence on human behaviour. It is usual for a person who holds positive attitudes towards a certain behaviour to perform the behaviour, and conversely, for a person who holds negative attitudes towards a certain behaviour not to perform it (Ajzen and Fishbein, 1977).

Similarly, attitudes can have favourable and unfavourable effects on Pro-Circular Behaviours ( $P$ $\mathrm{CB})$. For example, if a person holds unfavourable attitude towards buying remanufactured products, such as for example: it is very expensive, foolish and harmful in their opinion to do so, it is unlikely that they would proceed with the purchase. Understanding what are the behavioural attitudes (BA; of an individual or a group) towards certain Pro-Circular Behaviours is very important to help predict those behaviours and form interventions.

\subsubsection{Subjective Norms (SN)}

Subjective norms (SN) are the perceived social pressures to perform or not to perform certain behaviours. They are what a person believes their "important others" (e.g. family member, friend, boss) would think (either approve or disapprove) of them performing the behaviour (Ajzen, 1991). Ajzen (2006) divides the $\mathrm{SN}$ into two categories of Normative 
Beliefs (NB), which are: injunctive and descriptive. Injunctive beliefs are one's motivation to comply with the "important others". Whereas, descriptive beliefs refer to one's level of identification with a certain individual or group (Ajzen, 2006).

Both injunctive and descriptive Subjective Norms (SN) could have a positive or a negative impact on an intention to perform a Pro-Circular Behaviour (P-CB). For example, if a person's normative injunctive belief is that buying remanufactured products $(P-C B)$ is something their "important others", (i.e. boss), wants them to do, it is possible that because of this they may proceed with the purchase. Similarly, if a person holds a belief, that buying remanufactured products is a norm because it is something that their "important others" (i.e. friends) do, it is possible that this could also increase their intention to purchase (descriptive normative belief). Pro-Circular Behaviours (P-CB) need to become "the norm" (RWM Ambassadors, 2014) and identifying what people perceive the behavioural norms (NB) to be in the context of a Circular Economy, would help to design the appropriate interventions that could reshape their beliefs.

\subsubsection{Perceived Behavioural Control (PBC)}

Perceived Behavioural Control (PBC) is the third construct of the Theory of Planned Behaviour (TPB). It

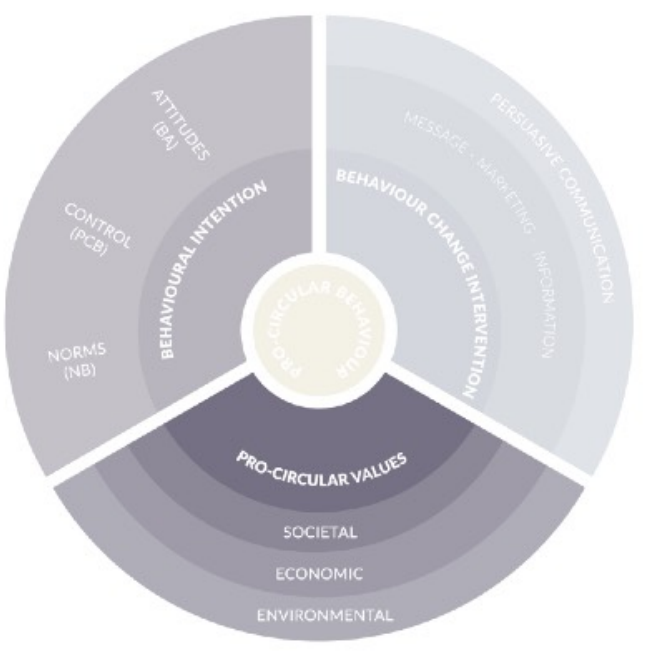

Figure 4. The P-CCM: Pro-Circular Values (P-CV) Stage.

specifies how easy or difficult people perceive it is to perform certain behaviours. Generally, factors such as the availability of resources or opportunities, should increase the likelihood of one's behavioural achievement. However, the presence of these factors alone does not always influence one's action, it is their perception towards the control (PBC) that has a strong influence on their actions (Ajzen, 1991).

Similarly, in context of Pro-Circular Behaviours, the Perceived Behavioural Control (PBC) can have a favourable on unfavourable impact on one's action. For example, if a person believes that they are able to buy a remanufactured product because that product is available in the shop, it is likely that this will impact their intention to purchase it.

The behavioural control (PBC) can have a direct impact on a behaviour, especially in instances where one's action relies on the availability of resources or opportunities. For example, if a person believes they are not able to buy the remanufactured product they want, because it is not available to them (e.g. is not produced), they will not proceed with the purchase. This example shows that despite any favourable attitudes, normative beliefs or intentions the person may hold towards the performing the behaviour, they will be unable to perform it. Therefore, it is crucial to identify people's control beliefs to form suitable resources and opportunities that would allow them to perform the Pro-Circular Behaviours (P-CB) or to help form interventions, aimed at changing the control perceptions by communicating the appropriate behaviour enablers (e.g. tools, opportunities) that are available to them.

\subsubsection{Behavioural Intention}

According the the TPB, a behaviour relies mutually on one's ability (an actual behavioural control) and intention (BI) to perform it. The strength of $\mathrm{BI}$ is a result of the attitudinal (BA), normative (NB) and control $(\mathrm{PBC})$ beliefs they hold. The stronger the $\mathrm{BI}$, the more likely is the performing of the behaviour. Therefore, the $\mathrm{BI}$ is considered to have a direct impact on a behaviour. (Ajzen, 2006)

This principle also applies to performing of the Pro-Circular Behaviours (P-CBs). For example, if a person's intention to buy a remanufactured product is low, because they hold unfavourable attitudes, normative and control beliefs towards it, it is likely that they will not proceed with the purchase. The TPB applied in the P-CCM could measure the probability levels of performing the P-CBs.

\subsubsection{Theory of Planned Behaviour - Research Methods}

Human behaviour can be identified through the appropriate survey research. The TPB Questionnaire (Ajzen, 2006) is a method commonly used to asses behavioural constructs and evaluate the intention to perform a behaviour. The questionnaire is supported 


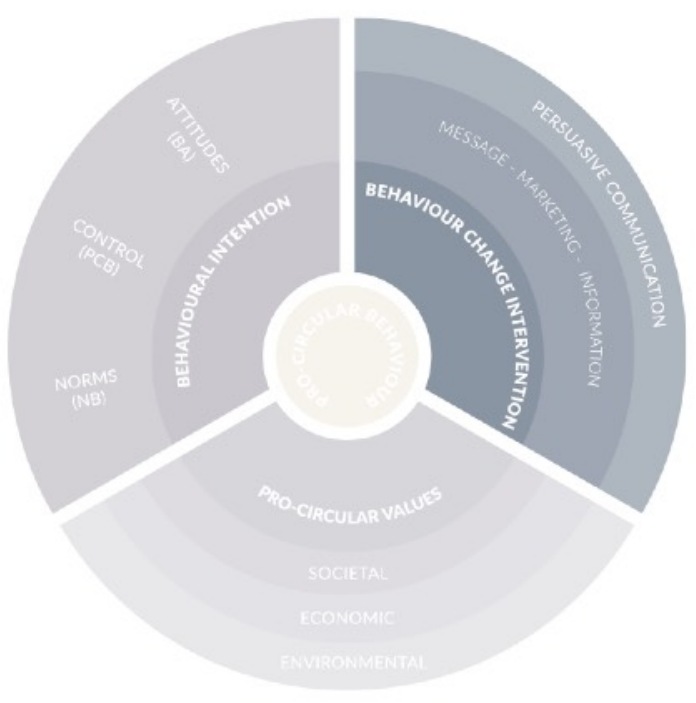

Figure 5. The P-CCM: Behaviour Change Interventions (BCI).

by a structural equation analysis, it can determine the strength a behavioural intention (BI) and its impact on behaviour. Furthermore, by evaluating the attitudinal , normative and control beliefs, this method provides and insight to cognitive foundations of behaviours (Ajzen, 2006).

It is possible, that TPB Questionnaire could help to determine the intention strength towards performing of a Pro-Circular Behaviour (P-CB) and enable those who want to change behaviours, to evaluate the attitudes, normative beliefs and control beliefs towards it. This knowledge could be used to explain certain behaviours and help form interventions.

\subsubsection{Defining Pro-Circular Behaviours}

TACT elements [Target (at which action is directed), Action, Context (in which action is performed) and Time (at which action is performed)] are used to define behaviours measured through the TPB. Setting the same TACTs in the constructs of attitudes, subjective norm and perceived behavioural control is important to ensure their compatibility. (Ajzen, 2002)

In line with this rule, Pro-Circular Behaviours (P$\mathrm{CB}$ ) need to be specified in accordance with TACT across all of the constructs of the TPB to ensure the compatibility. For example, an attitudinal statement related to a $\mathrm{P}-\mathrm{CBs}$, such as buying remanufactured products, can be defined as: "Buying a remanufactured computer for work next week, would be good/bad." The Target element here is a remanufactured computer, Action is buying, Context - work and Time next week. Similar TACT constructs need to be applied to its corresponding normative and control questions.

\subsection{Pro-Circular Values}

Values differ from individual to individual. They convey what is important to people in their life and are considered as a motivational construct of behaviour (Bardi \& Schwartz, 2003). Amongst attitudes, beliefs and behaviours, values can be important influencers of behaviour (Stern, 1999; Bardi \& Schwartz, 2003), especially when it comes to change on a large scale (Aerthon, 2015). Assessing values may help to underline the attitudes towards general targets such as freedom, equality (Ajzen, 2012) and environmental protection (Crompton and McMahon, 2011). Therefore, understanding one's value towards a greater good in the socio-economic and environmental domain, could help to explain or impact their Pro-Circular Behaviours.

The Pro-Circular Values (P-CV; Figure 4.) are a set of values that rate social, economic and environmental matters as important to oneself (Fig.4). Generally, values can reflect intrinsic and extrinsic goals. Intrinsic values are associated with concerns about bigger-than-self issues (Chilton et al., 2012). They result in a greater motivation to act in line with the community or environment. Whereas, extrinsic values relate to power, wealth or social recognition (Crompton and McMahon, 2011). Matters related to Circular Economy are considered to be of "biggerthan-self" importance, meaning that P-CVs are inherently intrinsic.

\subsubsection{Values - Research Methods}

Human values can be identified by quantitative survey research (Schwartz, 1992; Inglehart, 1997). The assumptions are that the appropriate survey instruments used in the P-CCM could help to determine levels of P-CVs one holds. In line with Inglehart's (1997) method, the intrinsic values can be measured by evaluating people's responses to questions about the "bigger-than-self" goals, such as global goals they may hold, rather than their individual goals.

In addition, a number of studies suggest using Likert (1932) type point scales in surveys, that can allow participants to express their values. These type of scales could be sufficient to measure the level of importance participants perceive the society, economy and environment have to them. The knowledge gained from these type of surveys, could be used to explain certain behaviours and help form more effective interventions in the last stage of the P-CCM - the Behaviour Change Intervention (BCl).

\subsection{Behaviour Change Interventions (BCIs)}


Behaviour Change Interventions (BCl; Figure 5.) are methods used to change human behaviours. In the P-CCM, Interventions aim to instigate Pro-Circular Behaviours (P-CB) by targeting the constructs of the Behavioural Intention (BI) and the Pro-Circular Values (P-CV). The interventions related to the $\mathrm{BI}$ aim to shift any of the attitudinal, normative or control beliefs, that may prevent the performance of a behaviour. The model proposes that to increase the effectiveness of targeting those beliefs (TPB constructs), the interventions should be designed by utilising the established P-CV held by an individual. It is also possible that the interventions could change one's P-CV.

Persuasive Communication (PC) is a type of $\mathrm{BCl}$ described as a "message that is intended to shape, reinforce, or change the responses of another or others" (Miller, 1980). It has the ability to influence people's beliefs, values, attitudes and behaviours (Burgoon, Hunsaker \& Dawson, 1994; The World Bank, 2009). Persuasive messages used in the P-CCM aim to convince the reader (or listener) to change their Attitudes (BA), Subjective Norms (SN) or Perceived Behavioural Controls PCB, in an attempt to encourage more Pro-Circular Behaviours (P-CB). It is also assumed that a persuasion which implements either intrinsic and extrinsic values (depending on an individual), could be influential in motivating a person to perform a $\mathrm{P}-\mathrm{CB}$.

A number of Circular Economy business models, initiatives and product ideas have developed over recent years. These however still remain niche and require mass adoption (European Commission, 2015b) in order to fully support the development of a Circular Economy. It is possible, that these models and ideas are not widely advertised to people or if advertised, they may not be communicated appropriately to achieve the mass adoption of the Pro-Circular Behaviours (P-CB). As mentioned by Ridley (Gould, 2016) it is now necessary to find the means to advertise the Circular Economy in order to shift people's behaviours. The persuasive communication is already present in some successful marketing strategies used to change people's behaviours (O'Shaughnessy and O'Shaughnessy, 2003). It is therefore possible, that the P-CCM could enable the adaptation of $\mathrm{P}-\mathrm{CBs}$ through the appropriately tailored message-based interventions.

\subsubsection{Using Attitudes, Norms, Perceived Control and Intentions to Enhance P-CBs}

When using the Theory of Planned Behaviour as a theoretical framework, interventions that target one's behavioural, normative beliefs and control beliefs, could motivate them to perform a behaviour. A successful intervention could encourage a person's positive attitude. In case of one's normative beliefs, this could be based on the perception that their "important others" would approve of them performing a behaviour or that they would too perform the same behaviour (Steinmetz et al., 2016)

The effects of persuasive communication (PC) messages on people's attitudes and normative beliefs were tested in the past and have proven to influence the intention (BI) to perform a behaviour (Ajzen, 1971). Therefore, the assumptions are that either the attitudinal, normative or control PC messages could also shift the intention to perform the Pro-Circular Behaviours. For example, if a person holds a positive normative belief (SN) and a favourable perception of the behavioural control (PCB), yet they refuse to buy a remanufactured product because their attitudes towards the product is negative, it is possible that exposing them to the attitudinal PC, could change their attitudes and effectively increase their behavioural intention (BI). .

\subsubsection{Pro-Circular Values in Behavioural Interventions}

\begin{tabular}{|l|l|l|}
\hline Values & Intrinsic & Extrinsic \\
\hline Social & $\begin{array}{l}\text { Nation's health } \\
\text { and well-being }\end{array}$ & $\begin{array}{l}\text { Championing } \\
\text { Company's } \\
\text { Social } \\
\text { Responsibility } \\
\text { Initiative }\end{array}$ \\
\hline Economic & $\begin{array}{l}\text { National } \\
\text { economic } \\
\text { growth }\end{array}$ & Saving money \\
\hline Environmental & $\begin{array}{l}\text { Clean and } \\
\text { sustainable } \\
\text { living } \\
\text { environment }\end{array}$ & $\begin{array}{l}\text { Meeting } \\
\text { Company's } \\
\text { Carbon } \\
\text { Footprint } \\
\text { Targets }\end{array}$ \\
\hline
\end{tabular}

The Behavioural Intervention (BI) in the P-CCM are built on individual differences - values. People's values towards a greater good in the socio-economic and environmental context could influence their P-CBs.

Table 2. Pro-Circular Values (PVC) - Social, economic and environmental values in intrinsic and extrinsic motivational context (examples based on an organisational purchasing behaviour).

Due to Pro-Circular Values being considered as predominantly intrinsic, it is possible that people who hold such values are more likely to perform the P-CBs. However, the P-CCM identifies the types of the Pro- 
Circular Values (Table.2; intrinsic or extrinsic; social, economic or environmental) of an individual or a specific group to use them as behavioural motivators in the PC messages. Holding intrinsic values alone may not be sufficient enough to influence one's behaviour towards the "bigger-than-self" goals (Webster and Riddell, 2006). Therefore, targeting values that are extrinsic, could be an alternative route to motivating Pro-Circular Behaviours (Table 2.). For example, an individual who decides to buy a locally remanufactured product because they rate national economic growth as very important (intrinsic value), may have the same impact on the economy, as an individual who buys the same product, but is driven by saving money (extrinsic value). The influence of both, intrinsic and extrinsic values on Pro-Circular Behaviours in different target groups needs further investigation.

\subsection{Testing of the PCCM (new heading)}

The proposed model aims to encourage further research into the existing behaviour change theories, particularly the Theory of Planned Behaviour, Persuasive Communication and human values across the various behavioural domains of a Circular Economy.

F) The model is currently being applied in a study within the retail refrigeration industry. All participants in the study purchase refrigeration equipment for their businesses. The study aims to positively impact their behaviour and encourage them to purchase a remanufactured equivalent.

Participants intentions prior to interventions are tested using a Theory of Planned Behaviour questionnaire. The questionnaire is followed by series of persuasive messages that integrate Pro-Circular Values. The influence of the persuasive communication on the behavioural intention to buy a remanufactured product is measured initially through an analysis of the results in the survey.

Results from the survey are used to develop a strategic marketing intervention plan. The plan will use the most effective persuasive communication (PC) messages drawn from the survey results. For example, in a scenario where an attitudinal message that combines extrinsic economic Pro-Circular value is declared by the majority of participants to have the highest impact on their behavioural intention (BI), this type of message would be utilised further.

As a result of the participants' exposure to the intervention, (persuasive communication (PC) messages in survey and marketing campaign) their future behaviour is monitored, through a log of any enquiries and/or purchases of remanufactured products. A further Theory of Planned Behaviour questionnaire will also be distributed to reassess the impact of the strategic marketing plan on the target group.

\subsection{Limitations (new heading)}

G) Research suggests that Persuasive Communication $(\mathrm{PC})$ combined with the Theory of Planned Behaviour (TPB) can instigate behaviour change (Ajzen, 1996). Where possible, it is recommended that after being exposed to the intervention, all participants are given the same questionnaire to reassess their behavioural intention. This reassessment is dependents on the participants availability and willingness to engage, which can be an obstacle to receiving a complete set of results. In addition, depending on the time lag between the first survey and the second survey, the participate is subject to a range of externalities (such as news, stress, policies etc.) which can impact (positively or negatively) the extent or nature of behaviour change.

As with any survey-based research it is important to wary that the participants answers may not be a true reflection of their actual beliefs.

\subsection{Conclusions}

Testing of the P-CCM is now in progress but due to it being a longitudinal study, no results have been obtained yet. However, based on the previous research on TPB, PC and values, the hypothesis is that these constructs, when combined together into a framework, could identify, change and maintain the Pro-Circular Behaviours. The analysis of the results will initially test this hypothesis, initiate change and further the development of the model (if necessary).

\section{References}

Ajzen, I. (1971) 'Attitudinal vs. Normative messages: An investigation of the differential effects of persuasive communications on behavior', Sociometry, 34(2), p. 263. doi: 10.2307/2786416.

Ajzen, I., \& Fishbein, M. (1977). Attitude-behavior relations: A theoretical analysis and review of empirical research.

Psychological Bulletin, 84, 888-918.

Ajzen, I. (1991) 'The theory of planned behavior', Organizational Behavior and Human Decision Processes, 50(2), pp. 179-211. doi: 10.1016/0749-5978(91)90020-t. 
Ajzen, I. (2002) Constructing a TPB questionnaire: Conceptual and methodological considerations. Available at: http://www.uni-bielefeld.de/ikg/zick/ ajzen\%20construction\%20a\%20tpb\%20questionnaire.pdf (Accessed: 9 February 2016).

Ajzen, I. (2006) CONSTRUCTING A THEORY OF PLANNED BEHAVIOR QUESTIONNAIRE. Available at: https://people.umass.edu/aizen/pdf/tpb.measurement.pdf (Accessed: 2 June 2015).

Ajzen, I. (2012) 'Values, attitudes, and behavior', in Methods, Theories, and Empirical Applications in the Social Sciences. Springer Nature, pp. 33-38.

Atherton, M. (2015) "Behaviour change towards a circular economy - part 1 - RSA", RSA, 22 October. Available at: https://www.thersa.org/discover/publicationsand-articles/rsa-blogs/2015/10/blog-behaviour-changefor-ce-part-1/ (Accessed: 20 September 2015).

APPSRG (2014) "Triple Win. The Social, Economic and Environmental Case for Remanufacturing." Available at: http://www.policyconnect.org.uk/sites/site_pc/files/ report/604/fieldreportdownload/apsrgapmg-triplewin.pdf (Accessed: 06 June 2015).

APPSRG and APPMG (2014) Triple Win: The

Economic, Social and Environmental Case for

Remanufacturing. Available at: http://

www.policyconnect.org.uk/sites/site_pc/files/report/604/ fieldreportdownload/apsrgapmg-triplewin.pdf (Accessed: 21 March 2015).

Bardi, A. and Schwartz, S.H. (2003) 'Values and behavior: Strength and structure of relations', Personality and Social Psychology Bulletin, 29(10), pp. 1207-1220. doi: 10.1177/0146167203254602.

Burgoon, M., Hunsaker, F.G., \& Dawson, E.J. (1994). Human Communication, 3rd ed. Thousand Oaks, CA: Sage, p. 177.

Crompton, T. and McMahon, S. (2011) Balancing intrinsic and extrinsic values. Available at: https:// www.theguardian.com/sustainable-business/socialpsychologists-environmental-values (Accessed: 22 January 2017).

DEFRA (2015) "UK response to European commission consultation of member states on the circular economy." Available at: https://www.gov.uk/government/ uploads/system/uploads/attachment_data/file/475862/ circ-economy-eu-consult-uk-response.pdf (Accessed: 10 December 2016).

Eagly, A. H., \& Chaiken, S. (1993). The psychology of attitudes. Harcourt Brace Jovanovich College Publishers.

Ellen MacArthur Foundation (2012) "Circular economy report - towards the circular economy Vol. 1." Available at: https://www.ellenmacarthurfoundation.org/ publications/towards-the-circular-economy-vol-1-aneconomic-and-business-rationale-for-an-acceleratedtransition (Accessed: 2 February 2015).

Ellen MacArthur Foundation (2013) "TOWARDS THE CIRCULAR ECONOMY. Opportunities for the consumer goods sector." Available at: https:// www.ellenmacarthurfoundation.org/assets/downloads/ publications/TCE_Report-2013.pdf (Accessed: 21 January 2017).

European Commission (2014) The circular economy. Available at: http://www.eesc.europa.eu/resources/docs/ the-circular-economy.pdf (Accessed: 12 October 2015).

European Commission (2015a) "COMMUNICATION FROM THE COMMISSION TO THE EUROPEAN PARLIAMENT, THE COUNCIL, THE EUROPEAN ECONOMIC AND SOCIAL COMMITTEE AND THE COMMITTEE OF THE REGIONS Closing the loop - An EU action plan for the Circular Economy." Available at: http:// eur-lex.europa.eu/legal-content/EN/TXT/?uri=CELEX: 52015DC0614 (Accessed: 19 December 2016).

European Commission (2015b) From Niche to Norm. Available at: http://www.gppq.fct.pt/h2020/_docs/ brochuras/env/from_niche_to_norm_sei.pdf (Accessed: 31 January 2017).

Fife-Schaw, C., Sheeran, P. and Norman, P. (2007) 'Simulating behaviour change interventions based on the theory of planned behaviour: Impacts on intention and action', British Journal of Social Psychology, 46(1), pp. 4368. doi: 10.1348/014466605×85906.

RWM Ambassadors (2014) EVER-DECREASING CIRCLES CLOSING IN ON THE CIRCULAR ECONOMY. Available at: http://www.rwmexhibition.com/files/ rwm14_ambassadors_doc.pdf (Accessed: 10 December 2016).

Gould, H. (2016) Can the advertising industry sell us waste-free living? Available at: https:// www.theguardian.com/sustainable-business/2016/jun/ 28/advertising-industry-waste-free-living-circulareconomy (Accessed: 11 September 2016).

Inglehart, R.F. (1997) Modernization and postmodernization: Cultural, economic, and political change in 43 societies. Princeton, NJ, United States: Princeton University Press.

Kollmuss, A. and Agyeman, J. (2002) 'Mind the gap: Why do people act environmentally and what are the barriers to pro-environmental behavior?', Environmental Education Research, 8(3), pp. 239-260. doi: 10.1080/13504620220145401.

Likert, R. (1932). A Technique for the Measurement of Attitudes. Archives of Psychology, 140, 1-55. 
Miller, G. R. (1980). On being persuaded: Some basic distinctions. In M. Roloff, \& G. R. Miller (Eds.), Persuasion: New directions in theory and research, 11-28. Beverly Hills, CA: Sage.

O'Shaughnessy, J. and O'Shaughnessy, N.J. (2003) Persuasion in advertising. London: Taylor \& Francis.

Rizos, V., Behrens, A., Kafyeke, T., Hirschnitz-Garbers, M. and loannou, A. (2015) The circular economy: Barriers and opportunities for SMEs. Available at: https:// www.ceps.eu/system/files/ WD412\%20GreenEconet\%20SMEs\%20Circular\%20Econ omy.pdf (Accessed: 15 October 2015).

Schwartz, S.H. (2012) 'An overview of the Schwartz theory of basic values', Online Readings in Psychology and Culture, 2(1). doi: 10.9707/2307-0919.1116.

The Scottish Government (2016) "Making things last - A circular economy strategy for Scotland." Available at: http://www.gov.scot/Resource/0049/00494471.pdf (Accessed: 23 January 2017).

Steinmetz, H., Knappstein, M., Ajzen, I., Schmidt, P. and Kabst, R. (2016) 'How effective are behavior change interventions based on the theory of planned behavior?', Zeitschrift für Psychologie, 224(3), pp. 216-233. doi: 10.1027/2151-2604/a000255.

Stern, P.C., Kalof, L., Dietz, T. and Guagnano, G.A. (1995) 'Values, beliefs, and Proenvironmental action: Attitude formation toward emergent attitude objects1', Journal of Applied Social Psychology, 25(18), pp. 1611 1636. doi: 10.1111/j.1559-1816.1995.tb02636.x.

Stern, Paul C.; Dietz, Thomas; Abel, Troy D.; Guagnano, Gregory A.; and Kalof, Linda, "A Value-BeliefNorm Theory of Support for Social Movements: The Case of Environmentalism" (1999). Huxley College on the Peninsulas Publications. Paper 1. http://cedar.wwu.edu/ hcop_facpubs/1

The CIWM (2014) The circular economy: What does it mean for the waste and resource management sector? Available at: http://www.ciwm-journal.co.uk/downloads/ CIWM_Circular_Economy_Report-

FULL_FINAL_Oct_2014.pdf (Accessed: 23 January 2017).

The World Bank (2009) Persuasion I CommGAP.

Available at: http://siteresources.worldbank.org/ EXTGOVACC/Resources/Persuasionweb.pdf (Accessed: 1 February 2017).

The World Bank (2014) "World Development Report 2015 Mind, society, and behaviour." United States: World Bank.

Webster, P., \& Riddell, P. (2006). The green divide:Times poll shows the gulf between words and action on the environment, The Times Online. London, UK.
Greaves, M., Zibarras, L. D. \& Stride, C. (2013). Using the theory of planned behavior to explore environmental behavioral intentions in the workplace. Journal of Environmental Psychology, 34, pp. 109-120. doi: 10.1016/j.jenvp.2013.02.003 